\title{
SHEAR-TENSION INTERACTION STRENGTH OF J-HOOK CONNECTORS IN STEEL-CONCRETE-STEEL SANDWICH STRUCTURE
}

\author{
Jia-Bao Yan ${ }^{1}$, J.Y. Richard Liew ${ }^{2, *}$ and Min-Hong Zhang ${ }^{3}$ \\ ${ }^{1}$ Research Fellow, ${ }^{2,3}$ Professor, Department of Civil \& Environmental Engineering, National University of Singapore, \\ E1A-07-03, One Engineering Drive 2, Singapore 117576 \\ *(Corresponding author: E-mail: ceeljy@nus.edu.sg)
}

Received: 7 December 2013; Revised: 15 January 2014; Accepted: 23 January 2014

\begin{abstract}
Steel-concrete-steel (SCS) sandwich structure with ultra-lightweight cement composite core has been developed and proposed for applications in offshore, bridge and building constructions. A new form of J-hook connector is introduced to bond the steel face plates and cement composite core to form an integrated unit which is capable of resisting extreme loads. Design formulae were proposed to predict the shear, tension, and their interaction resistances of J-hook connectors. Thirty push-out tests and eighteen tensile tests were carried out on steel-concrete-steel sandwich plates with J-hook connectors embedded in different kinds of concrete to determine their shear and tension resistance, respectively. Nonlinear finite element (FE) model was also developed to predict the load-slip and ultimate behavior of J-hook connectors under combined shear and tensile loads. Finally, the design formulae were validated by comparing the predicted results with those obtained from tests and FE analyses. The formulae may be used to evaluate the tension, shear, and shear-tension interaction resistances of the J-hook connectors in steel-concrete-steel sandwich composite structures.
\end{abstract}

Keywords: Shear resistance, Tension resistance, Shear-tension interaction, Push-out test, Tensile test, J-hook connector, Steel-Concrete-Steel sandwich

\section{INTRODUCTION}

Steel-Concrete-Steel (SCS) sandwich structure, consisting of two steel face plates and an internal sandwiched concrete core, has been developed and used in civil and offshore constructions due to its excellent strength to cost performance. Mechanical connectors or adhesive materials are commonly used to bond the steel face plates and the concrete core to resist interfacial slip and thus enhance the bending moment and transverse shear resistance. However, the cohesive material was found to be less effective due to the presence of imperfections on the bonding surface that often resulted in crack initiation on the steel and concrete interface at the service stage [1]. Different types of mechanical shear connectors have been developed for SCS sandwich structures to overcome this disadvantage. Angle shear connectors were developed and used in the SCS sandwich structures as the bonding measures in Japan (See Figure 1a) [2]. Due to the shallow embedment of the angle connectors, bond failure tended to occur under transverse shear loads unless additional stiffening plates or transverse reinforcements were provided. Double skin structure with overlapped headed shear studs (as shown in Figure 1b) was developed and it was initially proposed as the alternative form of submerged tunnels [3]. The disadvantage of double skin structure with overlapping connectors is that the tension separation behavior greatly depends on the strength of the concrete core and the overlapping length of the connector. Therefore its use is restricted to sandwich structure with very thick core. If the overlapping length is not adequate as in the case of thin core, lack of tensile bond may cause uplifting of the face plates which would compromise the integrity of the structure. Another representative type of connector was the friction welded bar connectors in 'bi-steel' structure as shown in Figure 1(c) [4]. The friction welded connectors were proved to be effective in providing longitudinal shear and transverse shear resistance [5]. However, the equipment for the friction welding limited the thickness of the sandwich plate within 200-700 $\mathrm{mm}$. To overcome this disadvantage and develop slim deck for offshore constructions, J-hook connectors were developed by Liew et al. [6] as shown in Figure 1(d). From the previous studies, 
sandwich structure with J-hook connectors exhibited excellent performances under impact, blast, and fatigue loadings [7, 8]. This type of structure has great potential for applications in hulls of cargo tank, bridge decks, offshore decks, shear walls, and protective structures as shown in Figure 2.

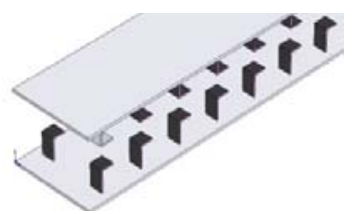

(a) SCS with angle connector

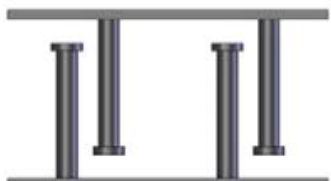

(b) SCS with headed shear studs

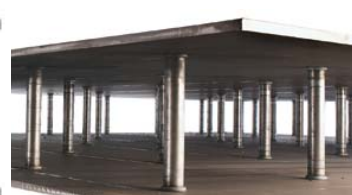

(c) Bi-steel structure

Figure 1. SCS with Different Shear Connectors

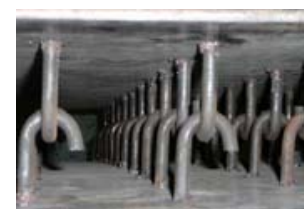

(d) SCS with J-hook connectors

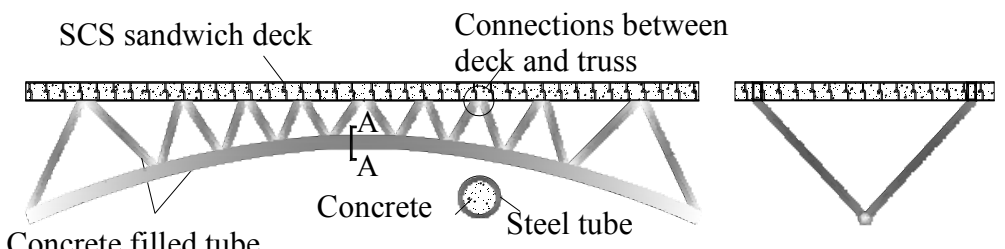

Concrete filled tube

A-A section

(a) Bridge deck

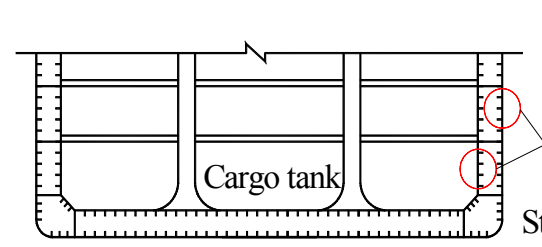

(b) Ship hull with stiffened steel plate
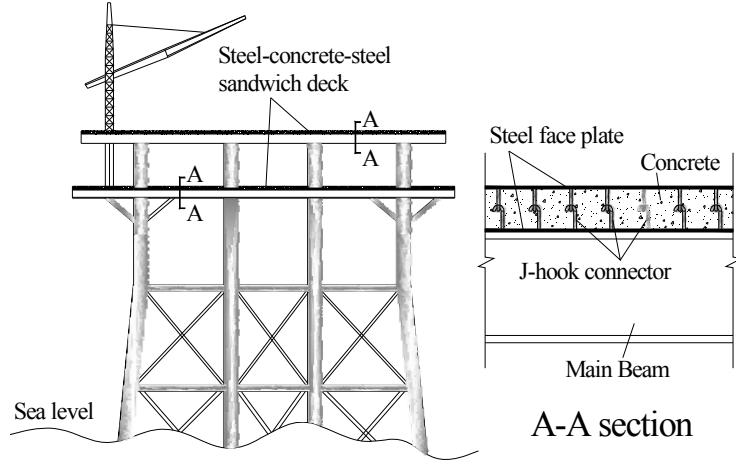

(d) Offshore deck
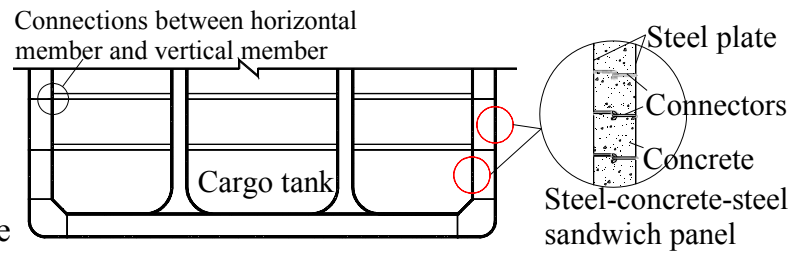

(c) Ship hull with SCS sandwich structure

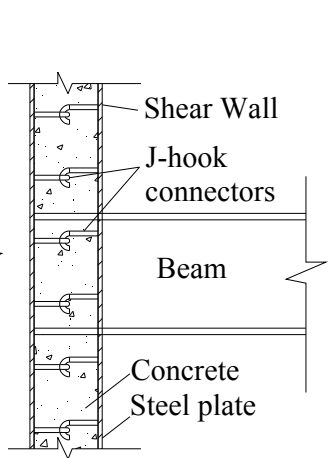

(e) Shear wall
Protective structure

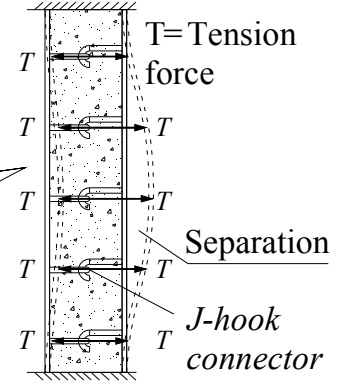

(f) Protective structure

Figure 2. Potential Applications of the SCS Sandwich Structure with J-hook Connectors

The shear connectors have to resist shear force due to the relative slip between the concrete core and steel when the SCS sandwich composite deck is subjected to lateral loads. The most critical scenario is that they are subjected to combined shear and tension as in the case of connections between the tension members and sandwich deck as shown in Figure 2a; connections between the horizontal beams and shear walls as shown in Figure 2c and 2d; high shear region of the beam and slab, and sandwich structures subjected to impact and blast as shown in Figure 2e and $2 \mathrm{f}$. The shear resistance of the headed shear stud connectors in the steel-concrete composite structures has been extensively studied by Viest [9], Driscoll and Slutter [10], Chinn [11], Steele [12], Davies [13], Mainstone and Menzies [14], Goble [15], Topkaya et al.[16], Ollgaard et al.[17], Oehlers and 
Bradford [18], An and Cederwall [19], and Pallarés and Hajjar [20]. Research works on tensile resistance of the headed shear studs connectors has been also carried out by Cook et al. [21, 22], Zamora et al. [23], Shirvani et al. [24], Eligehausen and Balogh [25], Eligehausen et al. [26], Fuchs et al. [27], Bode and Roik [28], Balogh et al. [29], Klinger and Mendonca [30], and Pallarés and Hajjar [31]. The resistance of the anchorage under combined shear and tensile load was studied by Pallarés and Hajjar [31], McMakin et al. [32], Sari et al. [33], and Mirza and Uy [34]. From these literatures, it can be found that most of these experimental and numerical studies were carried out on headed studs to investigate their resistances against tension and shear forces as well as combined shear and tensile forces. There is little information for the J-hook connectors [35]. Meanwhile, design formulae for headed studs are also available in PCI [36] and ACI 318 [37]. However, the design guides have not been developed and validated for J-hook connectors to be used for sandwich structures with different concretes grades.

The innovations of the new concrete materials also challenge the application of SCS sandwich structure with the novel J-hook connectors. The use of lightweight concrete (LWC) or ultra-lightweight cement composite (ULCC) in Steel-Concrete-Steel (SCS) sandwich composite structure may lead to significant reduction in weight which is critical for offshore and floating structures. LWC with compressive strength $30 \mathrm{MPa}$ and density $1450 \mathrm{~kg} / \mathrm{m}^{3}$ was used to produce slim deck for offshore structure [38]. More recently, ULCC with compressive strength $60 \mathrm{MPa}$ and density of $1450 \mathrm{~kg} / \mathrm{m}^{3}$ has been developed by the authors for producing SCS sandwich composite structures [39].

Since J-hook connectors are used together with ultra-lightweight cement composite material (ULCC), the resistances of J-hook connectors acting on ULCC need to be carefully determined. However, most of the studies or design guidelines were mainly developed for headed shear studs rather than J-hook connectors. Hence, these design guidelines need to be examined whether they are applicable to the design of J-hook connectors. In this research, design formulae were firstly developed to predict the shear resistance, tension resistance, and shear-tension interaction resistance of the J-hook connectors. Thirty push-out tests and eighteen tensile tests were carried out to obtain the shear and tension resistances of the J-hook connectors embedded in normal weight concrete (NWC), LWC, and ULCC, respectively. These push-out tests and tensile tests were also used to validate the finite element (FE) model. With the validated FE model, shear-tension interaction resistances of the J-hook connectors were obtained through the FE analysis (FEA). The test data and FEA results were used to validate the design formulae to predict shear-tension interaction resistance of the J-hook connectors in sandwich structures.

\section{RESISTANCES OF J-HOOK CONNECTORS}

A pair of interlocking J-hook connectors may be subject to longitudinal shear force, tensile force, and most likely combined shear and tension forces. The formulae for calculating the resistances against such forces are given in the following subsections.

\subsection{Shear Resistance}

Design codes such as ACI 318 [37] and Eurocode 4 [40] may be used to predict the shear resistance of headed shear studs. In Eurocode 4 [40], the design shear resistance of the J-hook connectors may be determined as 
$V_{u}=\frac{0.29 \alpha d^{2} \sqrt{f_{c k} E_{c}}}{\gamma_{V}} \leq \frac{0.8 f_{u} \pi d^{2} / 4}{\gamma_{V}}$

where $f_{u}=$ ultimate strength of the steel; $d=$ diameter of the connector, mm; $\alpha=0.2\left(h_{e f} / d+1\right)$ for $3 \leq h_{e f} / d \leq 4$, or $\alpha=1$ for $h_{e f} / d>4 ; h_{e f}=$ overall nominal height of headed stud connector, $\mathrm{mm} ; f_{\mathrm{ck}}=$ compressive strength of concrete cylinder; $E_{\mathrm{c}}=$ elastic modulus of concrete; $\gamma_{V}=$ the partial factor for connector and may be taken as 1.25 [40].

A semi-empirical formula to predict the design shear resistance was proposed for J-hook connectors by Yan et al. [35] based on calibration with results from push out tests:

$V_{J}=\frac{0.855 f_{c k}^{0.265} E_{c}^{0.469} A_{s}\left(h_{e f} / d\right)^{0.154}}{\gamma_{V}} \leq \frac{0.8 f_{u} \pi d^{2}}{4 \gamma_{V}}$

where $h_{e f}=$ nominal height of J-hook connector, $\mathrm{mm} ; f_{c k}$ in $\mathrm{MPa} ; E_{c}$ in $\mathrm{MPa} ; A_{\mathrm{s}}=$ cross sectional area of connector, $\mathrm{mm}^{2} ; f_{u}=$ ultimate tensile strength of the connector; $A_{\mathrm{s}}=$ cross sectional area of connector.

\subsection{Tension Resistance}

Four possible failure modes may take place when a pair of interlocked J-hook connectors is subjected to axial tension, which are concrete breakout failure, pullout failure, J-hook tensile failure, and punching shear failure of the steel plate to which the connector is welded (See

Figure 3). The formulae used to predict the resistances corresponding to these four failure modes are developed below.

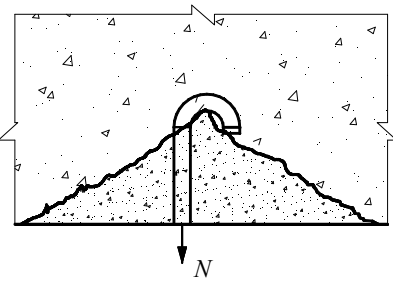

(a) Concrete breakout failure

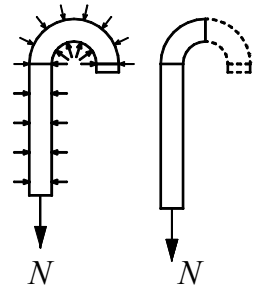

(b) Pullout failure

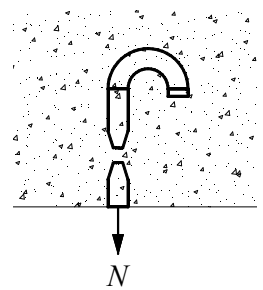

(c) Tensile fracture

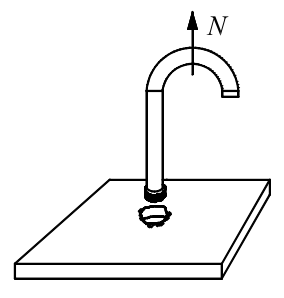

(d) Punching shear failure of steel plate

Figure 3. Failure Modes of the J-hook Subject to Direct Tension

\subsubsection{Concrete breakout failure}

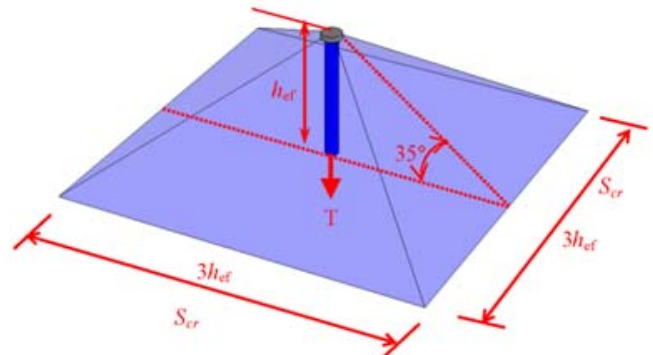

(a) Concrete capacity design method

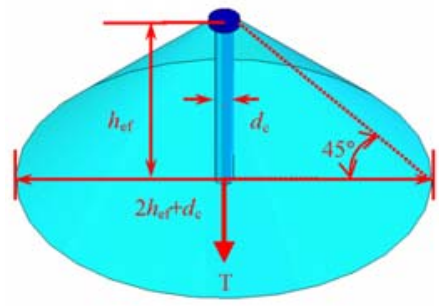

(b) 45-degree cone method

Figure 4. Illustration on Methods of Calculating Concrete Breakout Resistance 
The concrete breakout resistance may be calculated by the 45-degree concrete cone model, which is obtained by modifying CEB-FIP [41] and ACI 349 [42] as

$N_{C B}=\frac{0.333 \sqrt{f_{c k}} A_{N}}{\gamma_{c}}$

where $A_{N}=\pi h_{e f}^{2}\left(1+d / h_{e f}\right)$ is the projected area of the cone failure surface as shown in

Figure 4; $d=$ diameter of the connector. $\gamma_{c}=$ partial factor for concrete and may be taken as 1.5 in accordance to with Ref. [43].

\subsubsection{Pullout failure}

The pullout failure of the connector is due to compression failure of the concrete surrounding the connector as shown in Figure 3b. The design pullout resistance of the connector $N_{p l}^{\prime}$ can be calculated by modifying design formulae in ACI [37] as

$N_{p l}^{\prime}=\psi_{c, p} N_{P} / \gamma_{c}$

where $\psi_{c, p}=1.4$ for connectors in uncracked concrete and 1.0 for connectors in cracked concrete under service load. $N_{P}=$ pullout resistance of connector. For hook shaped connectors, the pullout resistance $N_{\mathrm{p}}$ can be calculated by [37]:

$N_{P}=0.9 f_{c k} e_{h} d$

where $e_{h}=$ distance from the inner surface of the shaft of a J-hook connector to the outer tip of the J-hook as shown in Figure 6, and $3 d \leq e_{h} \leq 4.5 d$.

However, for a pair of J-hook connectors, the influence of interlocked J-hook should be considered. The tensile force acting on one connector will be partially transmitted directly to the other connector and partially to the surrounding concrete. Therefore, the tension resistance of a pair of J-hook connectors consists of two parts i.e. pullout resistance of a single J-hook and hook straightening resistance of the bare J-hook. This can be expressed as the following

$N_{P l}=N_{p l}^{\prime}+N_{h s}$

where $N_{h s}=$ bare hook straightening resistance, and equal to $0.116 f_{y} d^{2} / \gamma_{M 0} ; f_{\mathrm{y}}=$ yield strength of the steel; $N_{p l}^{\prime}$ can be obtained from Eq. 4a. $\gamma_{M 0}=$ partial factor and may be taken as 1.00 for connector design in accordance to Ref. [44].

\subsubsection{J-hook tension failure}

Tensile fracture of the J-hook connector may occur as shown in

Figure 3c. The tension resistance of the steel shank $N_{S}$ may be estimated as 
$N_{S}=\frac{\left(\pi d^{2} / 4\right) f_{u s}}{\gamma_{M 2}}$

where $f_{u s}=$ ultimate tensile strength of the steel connector; $\gamma_{M 2}=$ partial factor and may be taken as 1.25 for connector design in accordance to Ref. [45].

\subsubsection{Punching shear failure of the steel face plate}

The punching shear failure of the steel face plate is shown in

Figure 3d. In Eurocode 3 [44], the punching shear resistance $N_{p s}$ of the steel face plate that the connectors were welded to is calculated by

$N_{p s}=\frac{\pi d t\left(f_{y} / \sqrt{3}\right)}{\gamma_{s}}$

where $d=$ diameter of the connector; $t=$ thickness of the steel plate; $f_{y}=$ characteristic yield strength of the steel plate; $\gamma_{s}=1.0$ is the partial factor for steel plate [44].

\subsubsection{Design tension resistance of J-hook connectors}

In summary, the tension resistance of the J-hook connectors may be determined by the smallest value of the resistances calculated by Eqs. (3), (5), (6), and (7). Hence, the tension resistance of the J-hook connector in the ULCC can be determined by

$$
N_{u}=\min \left(N_{C B}, N_{p l}, N_{s}, N_{p s}\right)
$$

\subsection{Interaction of Shear and Tension}

The design resistance of the connector under combined shear and tensile loads may be calculated as follow [36, 37]:

1) If applied shear force $V \leq 0.2 V_{u}$, full resistance in tension shall be permitted:

$N \leq N_{u}$

2) If applied tensile force $N \leq 0.2 \phi N_{u}$, full resistance in shear shall be permitted:

$V \leq V_{u}$

3) If $V>0.2 \phi V_{u}$ and $N>0.2 \phi N_{u}$, then

$\frac{V}{V_{u}}+\frac{N}{N_{u}} \leq 1.2$ 
Another expression of the shear-tension interaction relationship is given as

$$
\left(\frac{V}{V_{u}}\right)^{5 / 3}+\left(\frac{N}{N_{u}}\right)^{5 / 3} \leq 1.0
$$

where, $V=$ design shear force; $V_{\mathrm{u}}=$ design shear resistance of the connector calculated by Eq. 1 or 2 ; $N=$ design tension force, $N_{u}=$ design tension resistance of the connector calculated by Eq. 8 .

Eqs. 9(a-c) and Eq. 10 may be used to estimate the resistance of J-hook connectors subjected to combined shear and tension forces. Their accuracies will be evaluated based on calibration with test data and results from finite element analysis which will be reported in Section 5. Based on experimental and numerical calibration, suitable formulae will be recommended for design purpose. These recommendations will be used for the evaluation of SCS sandwich section subjected to moment and transverse shear resistance.

In Eqns. 1-10, partial factors in Eurocodes [40, 43-44] were used to calculate the corresponding design resistances of J-hook connectors. However, for comparision with test results, these factor should be taken as 1,0 (i.e., $\gamma_{C}=\gamma_{s}=\gamma_{M 2}=1.0$ ) for the calculation of the resistance of J-hook connector.

\section{PUSH-OUT AND TENSILE TESTS ON J-HOOK CONNECTORS}

The shear and tension resistances of the J-hook connectors were studied through push-out tests and tensile tests, respectively. These push-out and tensile tests were used to validate the design formulae to calculate the shear and tension resistance of J-hook connector.

\subsection{Concrete Materials used in Push-out and Tensile Tests}

A type of fibre-reinforced ultra-lightweight cement composite (ULCC) was developed with 28-day compressive strength about $60 \mathrm{MPa}$ and a low density of $1450 \mathrm{~kg} / \mathrm{m}^{3}$ [39]. Compared with typical normal weight concrete with similar strength $(60 \mathrm{MPa})$ and density of $2400 \mathrm{~kg} / \mathrm{m}^{3}$, the ULCC has higher specific strength (strength-to-density ratio). Besides a $40 \%$ weight reduction from normal weight concrete, the ULCC exhibits comparable tensile strengths to the normal weight concrete of similar compressive strength. Due to its porous structure, the ULCC has lower modulus of elasticity approximately $50 \%$ that of normal weight concrete.

Table 1 shows mechanical properties of different concrete mixtures at 28 days. The stress-strain curve of the ULCC under compression was compared with the NWC of similar compressive strength as shown in Figure 5. The ULCC was made of ordinary Portland cement, cenospheres, 6 $\mathrm{mm}$ polyvinyl alcohol (PVA) fibres, silica fume, and chemical admixtures. The PVA fibres $(0.5 \%$ by volume) were used to reduce the brittleness of the ULCC. 
Table 1. Basic Material Properties of Various Types of Concretes at Age 28-day

\begin{tabular}{|l|c|c|c|c|c|c|c|c|}
\hline \multicolumn{1}{|c|}{ Concrete } & $\begin{array}{c}w \\
\left(\mathrm{~kg} / \mathrm{m}^{3}\right)\end{array}$ & $\begin{array}{c}f_{\text {cu }} \\
(\mathrm{MPa})\end{array}$ & $\begin{array}{c}f_{\text {ck }} \\
(\mathrm{MPa})\end{array}$ & $\begin{array}{c}f_{\text {ck }} / f_{\text {cu }} \\
\text { Ratio }\end{array}$ & $\begin{array}{c}f_{\text {sp }} \\
(\mathrm{MPa})\end{array}$ & $\begin{array}{c}f_{\mathrm{t}} \\
(\mathrm{MPa})\end{array}$ & $\begin{array}{c}E_{c} \\
(\mathrm{GPa})\end{array}$ & $u$ \\
\hline ULCC C60 & 1450 & 64.0 & 64.6 & 1.01 & 4.4 & 6.7 & 16.0 & 0.25 \\
\hline LWC C25 $^{+}$ & 1602 & - & 26.7 & - & 2.2 & - & 17.5 & 0.22 \\
\hline LWC C45 $^{+}$ & 1852 & 51.7 & 47.9 & 0.93 & 3.3 & - & 18.0 & 0.22 \\
\hline LWC C60 $^{+}$ & 1883 & - & 60.6 & - & 4.6 & - & 20.8 & 0.24 \\
\hline LWC C30 & 1450 & 24.0 & 24.0 & 1.00 & - & 1.8 & 11.7 & 0.24 \\
\hline LWFC C30 & 1450 & 30.0 & 28 & 0.93 & - & 4.5 & 12.3 & 0.22 \\
\hline NWC C30 & 2337 & 46.1 & 33.1 & 0.72 & 3.9 & 4.0 & 20.2 & 0.24 \\
\hline NWC C45 & 2400 & 62.4 & 48.7 & 0.78 & 4.4 & - & 24.0 & 0.25 \\
\hline NWC C80 & 2365 & - & 70.0 & - & 4.8 & - & 39.0 & 0.25 \\
\hline HPC & 2750 & - & 180 & - & 11.8 & - & 60.0 & 0.25 \\
\hline
\end{tabular}

+ Natural sand was used to replace fine expanded clay lightweight aggregate; LWFC $=$ lightweight fiber reinforced concrete; $w=$ density; $f_{\mathrm{cu}}=$ compressive strength of cube; $f_{\mathrm{ck}}=$ compressive strength of cylinder; $f_{\mathrm{sp}}=$ splitting strength of cylinder; $f_{\mathrm{t}}=$ flexural tensile strength of prism; $E_{\mathrm{c}}=$ elastic modulus; $u=$ Poisson's ratio.

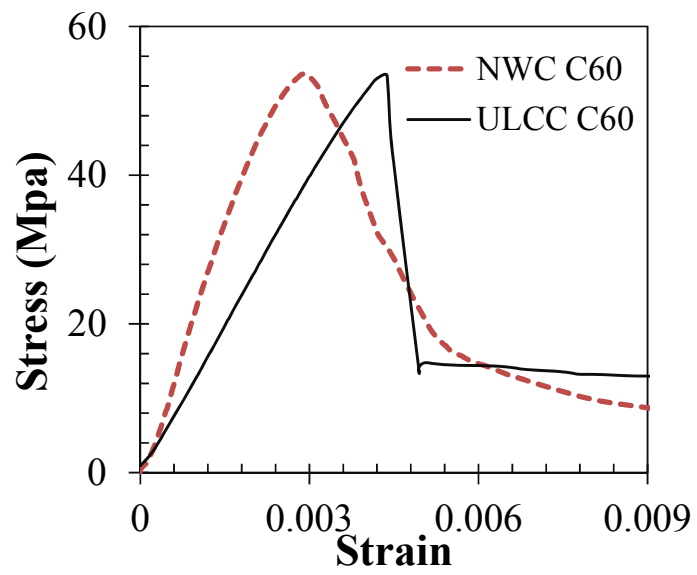

Figure 5. Comparison of Stress-strain Curves between NWC and ULCC

The LWC was also used in the tests. Ordinary Portland cement and expanded clay type of lightweight coarse and fine aggregate with an average particle density of $1000 \mathrm{~kg} / \mathrm{m}^{3}$ and maximum particle size of $8 \mathrm{~mm}$, and water were used to produce the lightweight concrete. In some mixtures the natural sand was used to replace the fine aggregate. In order to improve the tensile strength of the LWC, steel fibres were used in several specimens. The properties of the LWC are shown in Table 1.

The NWC was made of Portland cement, granite coarse aggregates (Max size $=20 \mathrm{~mm}$ ), natural sand, and water. Densities for the natural sand and granite aggregate were 2560 and $2610 \mathrm{~kg} / \mathrm{m}^{3}$, respectively.

Normal weight high performance concrete (HPC) with a compressive strength of $180 \mathrm{MPa}$ was used in one specimen to investigate the effects of high compressive strength and elastic modulus on the confinement. 


\subsection{Push-out Test on J-hook Connectors}

The shear resistance of connectors embedded in concrete is traditionally obtained from the push-out test. In Eurocode 4 [40], a recommended test standard for headed shear studs is given. However, this proposed method is not suitable for a pair of directly interacted connectors. A test method recommended by Xie et al. was used for the push-out test on the J-hook connectors that was originally developed for the friction welded connectors in Bi-steel structures [45].

\subsubsection{Test setup}

The geometry of the sandwich specimens and load apparatus for push-out tests are shown in Figure 6. A pair of J-hook connectors was welded separately on two steel plates as shown in Figure 6 . Three types of concretes NWC (C30, C45, and C60), LWC (C25, C30, and C45) and ULCC were used in this test. The diameters of the J-hook connectors were 10, 12, 16 and $20 \mathrm{~mm}$. Four different thicknesses of concrete cores 80,100,150, and $200 \mathrm{~mm}$ were investigated. Dimensions and properties of the materials for thirty specimens are given in Table 2.

All the specimens were cured and tested at 28 days after the casting. A steel plate spreader was used to averagely distribute the load from the actuator to the concrete core. The interfacial slips between the concrete core and steel face plates were recorded by the Linear Varying Displacement Transducers (LVDTs).

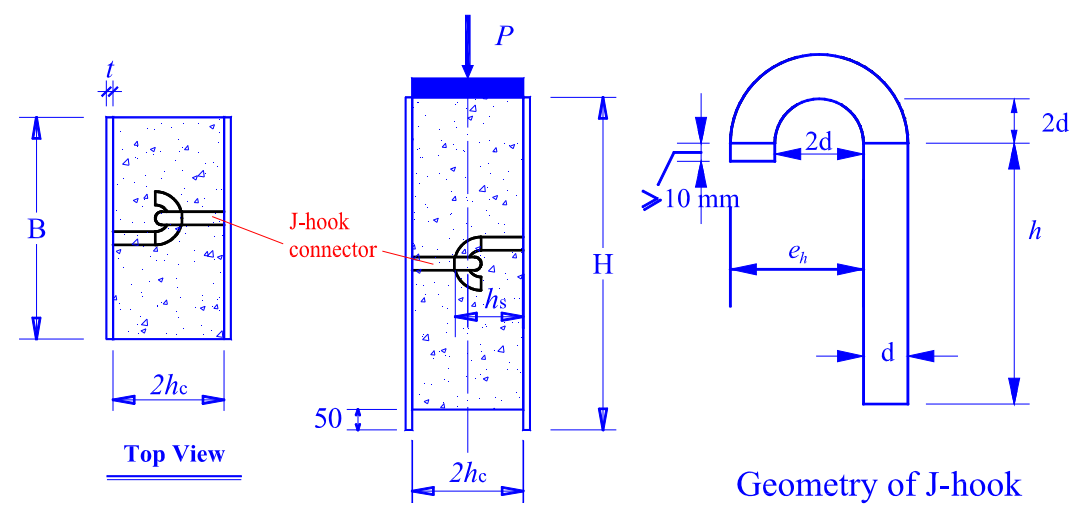

Figure 6. Push-out Test Setup and Geometry of Specimen

\subsubsection{Test results and validation of design equation}

The shear resistance of one J-hook connectors and the failure modes of the specimens were listed in Table 2. Three types of failure modes were observed from the test i.e. shear failure across the connector's shank, concrete failure, and shear failure across the welding toe. The detailed information of the failure modes and shear-slip behaviour of the J-hook connectors was reported by Yan et al. [35].

The shear resistances predicted by Eurocode 4 [40] and Eq. 2 are compared with the test results in Figure 7 and Table 2. It can be observed that both equations underestimate the shear resistance of J-hook connectors. There are no significant differences in terms of average test-to-prediction ratios (mean) and coefficient of variance (COV) between the proposed model (Eq. 2) (mean=1.26, $\mathrm{COV}=0.16$ ) and the Eurocode $4[40]$ (mean=1.22, $\mathrm{COV}=0.18)$. However, the proposed model (Eq. 2) offers safer predictions with test-to-prediction ratio is larger than 1.0 compared with the Eurocode 4 method [40]. 


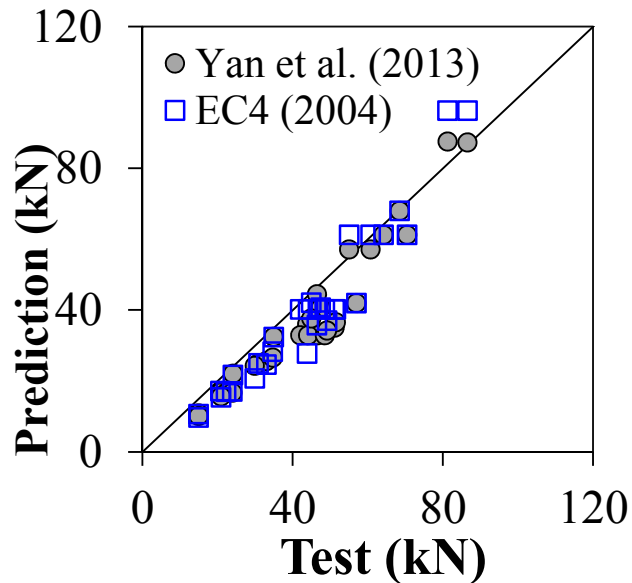

Figure 7. Comparisons of Shear Resistance between Predictions and Test Results
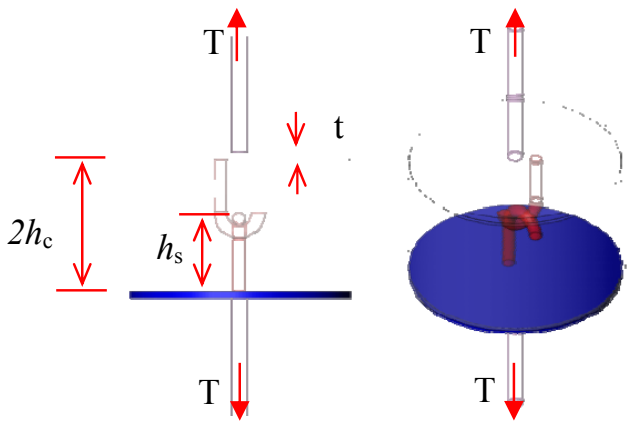

Figure 8. Tensile Tests on J-hook Connector

Table 2. Details of Push-out Test Specimens

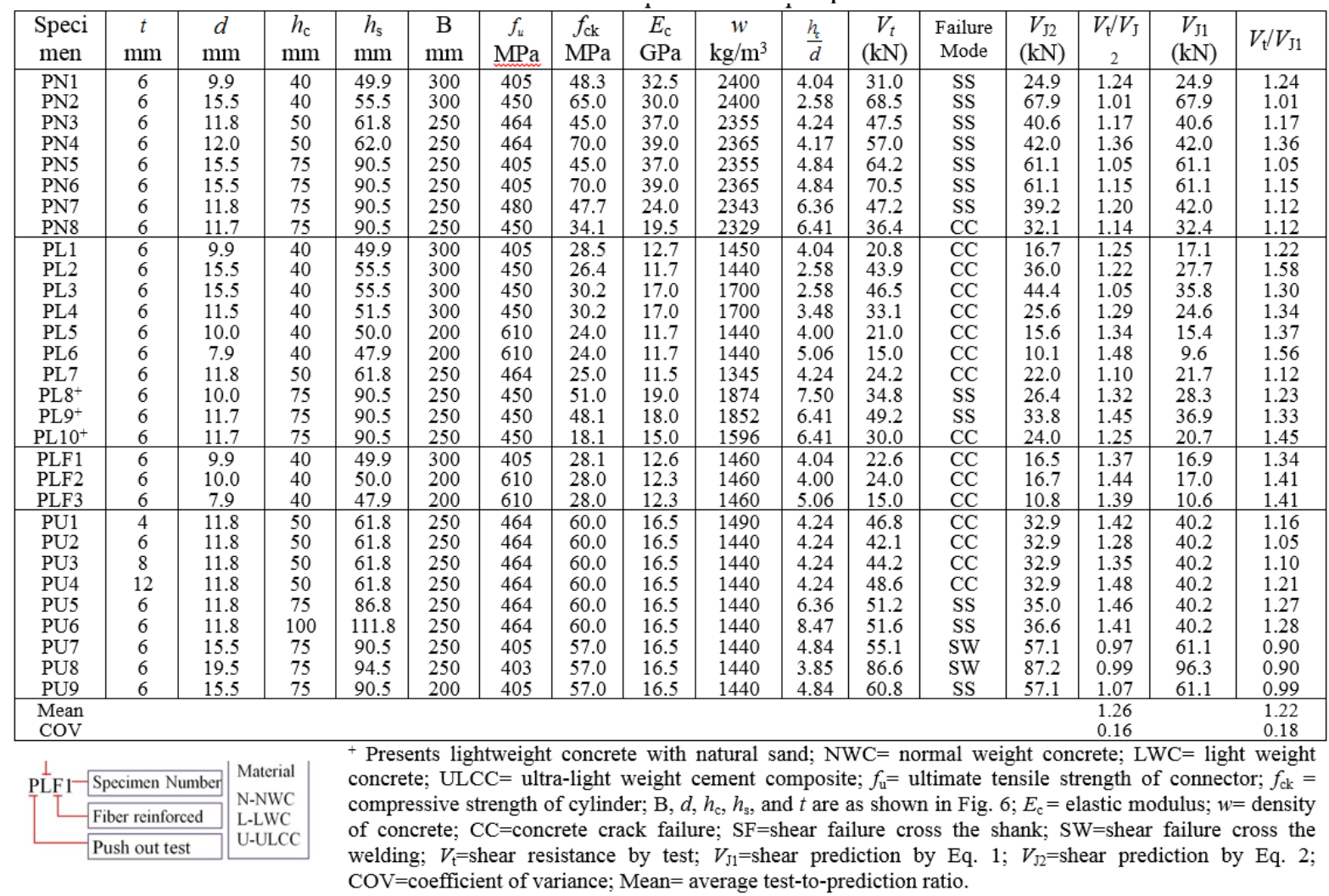

\subsection{Tensile Test of J-hook Connectors}

The tension resistance of a pair of interlocked J-hook connectors in SCS sandwich structure is obtained from the direct tensile test [46].

\subsubsection{Test setup}

The test setup is shown in Figure 8. Details of the specimens are summarized in Table 3. Steel moulds were used in the specimens to simulate confinement of surrounding concrete in the SCS sandwich structures. The diameter of the cylindrical specimen was $200 \mathrm{~mm}$. The height of the 


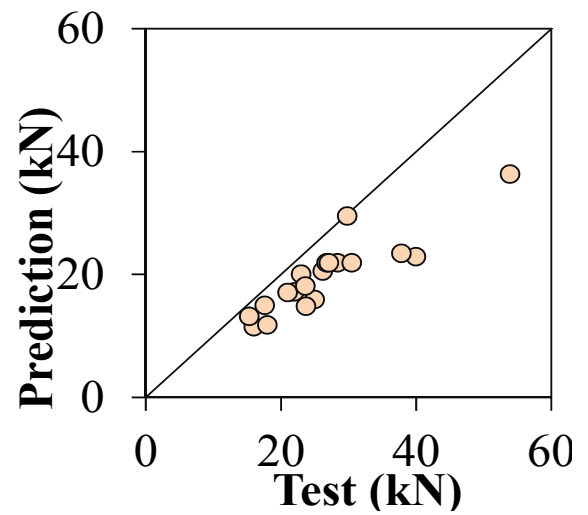

Figure 9. Comparisons of Tension Resistance between Predictions and Test Results

\section{FINITE ELEMENT ANALYSIS ON SHEAR-TENSION INTERACTION OF J-HOOK CONNECTORS}

Finite element (FE) software package ABAQUS was used for the analysis of the shear-tension interaction resistance of the J-hook connectors. ABAQUS/Standard implicit type of solver was used for the solution.

\subsection{Material Models of the Finite Element Analysis}

\subsubsection{Material models for concretes}

Concrete damage plasticity model in ABAQUS was chosen for NWC, LWC, and ULCC. In this model, the uniaxial compressive and tensile behaviors need to be defined. The stress-strain characteristics of ULCC were obtained from compressive and tensile tests as shown in Figure 10a. It can be observed that stress of ULCC firstly increases almost linearly to the peak $60 \mathrm{MPa}$ and then suddenly drops to about $20 \mathrm{MPa}$ that is one third of the peak stress $60 \mathrm{MPa}$ due to the cracking of the concrete. The residual strength is due to the addition of $0.5 \%$ per volume PVA fibers $(6 \mathrm{~mm}$ long). Based on the material tests, elastic modulus of ULCC is $17.5 \mathrm{GPa}$ and Poisson's ratio is 0.25 . The same methods were applied to the NWC and LWC that were involved in this study. Other parameters including flow potential eccentricity of 0.6 , dilation angle of $36^{\circ}$, and ratio of the biaxial/uniaxial compressive strength ratio of 1.16 were set for this plastic damage model.

\subsubsection{Material models for steel face plates and connectors}

Typical elastic and plastic isotropic material model in ABAQUS material menu was chosen for steel material. A bi-linear stress-strain behavior was used for FE simulation as shown in Figure 10b. The stress-strain relationship behaves linearly up to the yield point followed by a stress hardening behaviour. The mechanical properties of the steel plates and connectors obtained from tensile tests were tabulated in Table 2 and Table 3, respectively. 


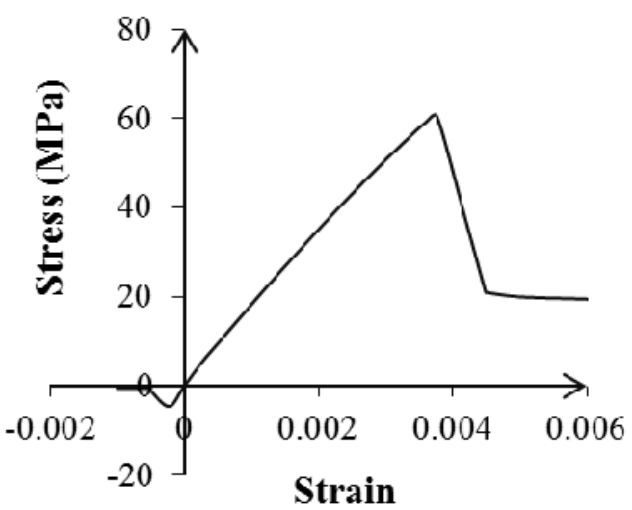

(a) Stress-strain curves of ULCC

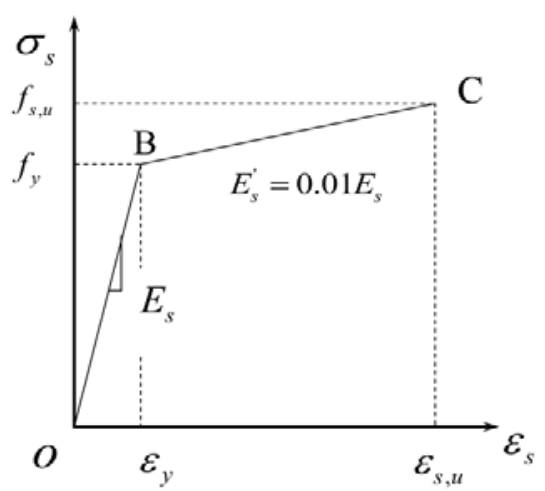

(b) Stress-strain mode for steel

Figure 10. Stress-strain Models for ULCC and Steel

\subsection{Geometry, Element Type and Mesh Size Study}

\subsubsection{Geometry}

A pair of J-hook connectors was simplified to two rods linked at the center by nonlinear spring element as shown in Figure 11.

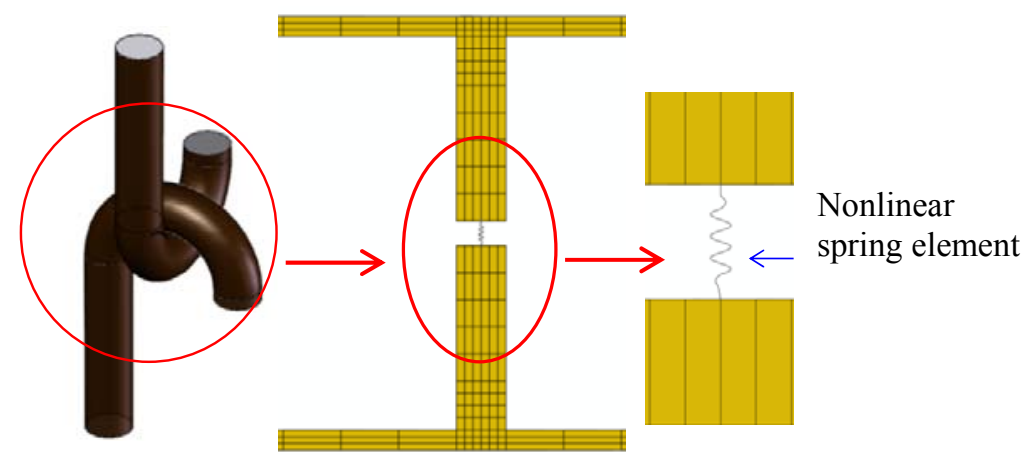

Figure 11. Simplification of J-hook Connector

The tension-elongation behaviors of the spring element were obtained from the tensile tests on the J-hook connectors as presented in section 3.3. Considering symmetry of the loading and geometry of the specimen, only half of the specimen was modeled as shown in Figure 12. From this figure, it can be seen that different components of specimens in the FE model such as steel face plates, concrete, connector and loading plate are simulated. Symmetrical constraints were applied to the surfaces as shown Figure 12.

Contact pairs were defined between steel plate and concrete and between connectors and concrete.

\subsubsection{Element type and mesh size study}

Three dimensional eight node continuum element (C3D8R) was chosen to simulate the concrete core, connectors, and steel face plates. At different locations, different mesh sizes were used to make a balance between the FE analysis accuracy and computing processing time. A mesh sensitivity study of FE analysis was also carried out. Three cases with different mesh sizes were studied and they are coarse mesh, medium mesh and fine mesh are shown in Figure 13 (a)-(c), respectively. For coarse meshes, concrete mesh size in the vicinity of connector is $8 \times 8 \times 8 \mathrm{~mm}^{3}$ and 
other regions are $25 \times 25 \times 12.5 \mathrm{~mm}^{3}$ and mesh size for connector is $2 \times 2 \times 4 \mathrm{~mm}^{3}$. For medium mesh size, the concrete in vicinity of connector is $6 \times 6 \times 3 \mathrm{~mm}^{3}$ and connector is $1.5 \times 2 \times 3 \mathrm{~mm}^{3}$. Finally, for fine mesh size, the concrete mesh in the vicinity of connector is $2 \times 4 \times 2 \mathrm{~mm}^{3}$ and for connector is $1 \times 1 \times 1 \mathrm{~mm}^{3}$.

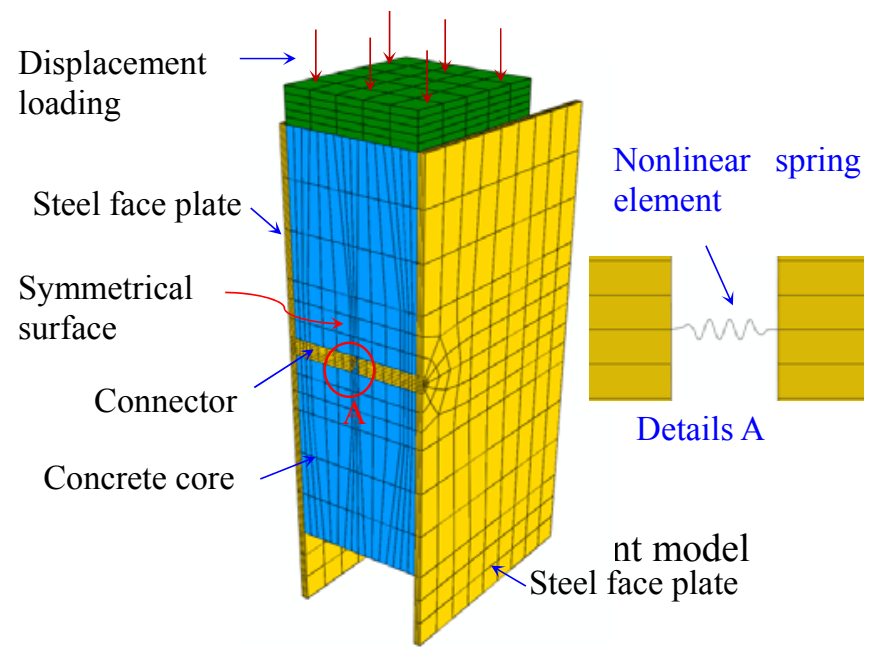

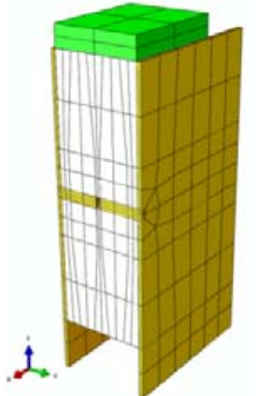

(a) Coarse mesh size

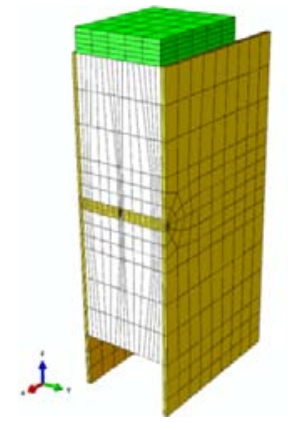

(b) Medium mesh size

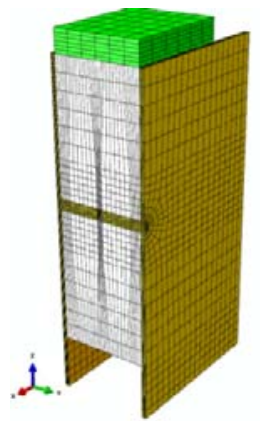

(c) Fine mesh size

Figure 13. FE Model with Different Mesh Size
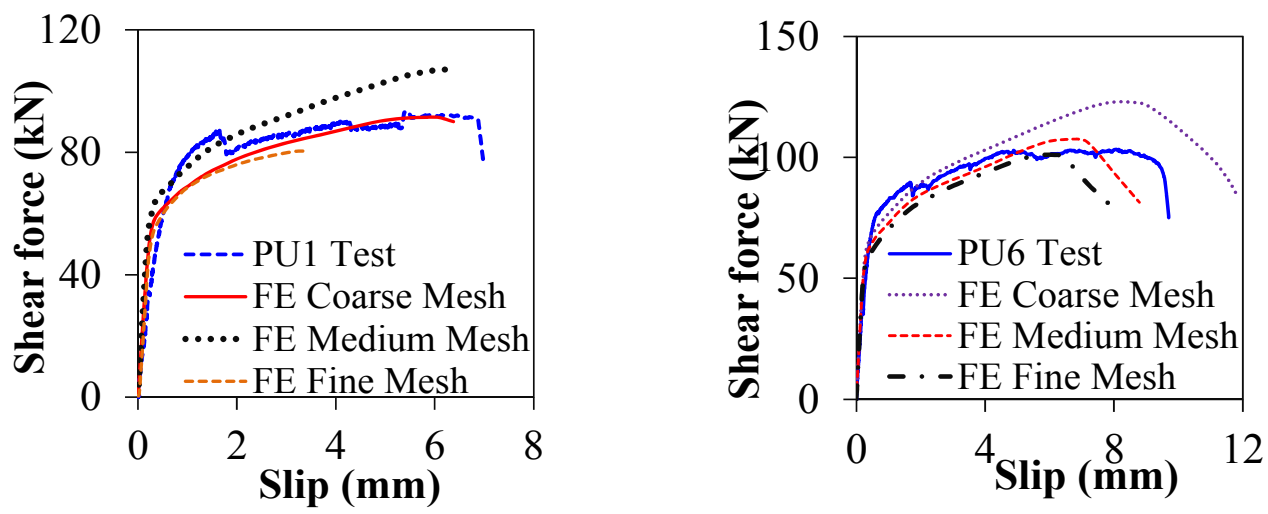

Figure 14. Effect of the Mesh Size on the FE Simulation

The load-slip curves by the FE analysis with different mesh sizes are compared with the experimental curves of specimens PU1 and PU6 in Figure 14. It can be observed that FE model with fine or medium mesh size offers better agreements than model with coarse mesh, but fine mesh will lead to more elements and restraining nodes for the contact and thus it increase the computation time. The medium mesh size is adopted for further analyses for computational efficiency and result accuracy. 


\subsubsection{Contact definition and study of contact friction coefficient}

Contact pairs were defined between steel plates and concrete, and between connectors and concrete. Hard contact and penalty friction properties were specified for the interaction at the steel and concrete interface in the normal direction and the in-plane direction, respectively. Hard contact property is defined that the pressure is transferred once two interacting surfaces touch whereas no pressure is transferred once separated. For penalty friction contact, friction interaction was specified when the two interacting surfaces were in contact. In the penalty friction property, the friction coefficient is an empirical value less than one that needs to be determined further. Two cases of push-out tests on PU1and PU5 with varying friction coefficients from 0 to 0.5 were studied to determine the proper friction coefficient for further FE analysis. The influence of the different friction coefficients on the FE simulation is shown in Figure 15. It can be observed that larger friction coefficient leads to higher shear resistance. The ultimate shear resistance of the connector increases about $10 \%$ when the friction coefficient increases from 0 to 0.5 . The FE simulation using friction coefficient $\mu=0.4$ was found to best fit the load slip curves obtained from the push out tests.
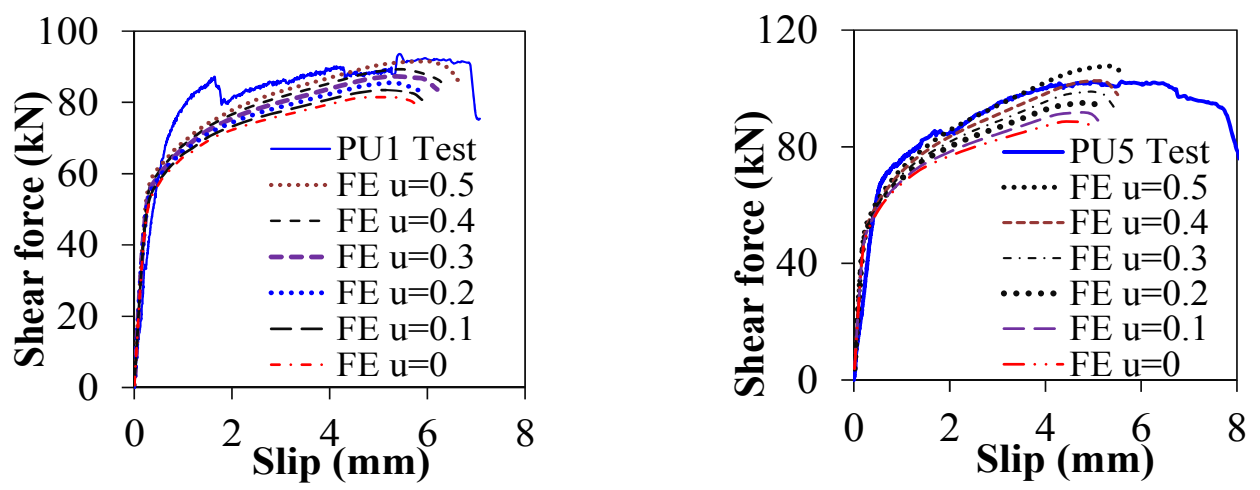

Figure 15. Effect of the Friction Coefficient on the FE Simulation

\subsection{Validations of the FE Model}

The validations of the $\mathrm{FE}$ analysis against push-out tests and tensile tests were carried out to evaluate the accuracy of the FE analysis.

Thirteen push-out tests carried out in Section 3 were chosen for the validation of the FE model, and the same specimens were then used in further analysis on shear-tension interaction resistance of J-hook (as listed in Table 4). The shear force versus slip curves obtained from the push-out tests were compared with the curves by FE analysis in Figure 16(a)-(f). It can be seen that the load-slip curves obtained from the FE analysis resembles well the experimental load-slip curves. The experimental ultimate shear resistances of one J-hook connector are compared with the FE analysis in Table 2. From this table, it can be found that the average test-to-FE prediction ratio is 0.99 with a $\mathrm{COV}$ of 0.05 . From these comparisons of shear-slip behaviors and ultimate shear resistance, it can be concluded that the developed FE model is capable of predicting the structural behaviors of the J-hook connectors under shear loads. 


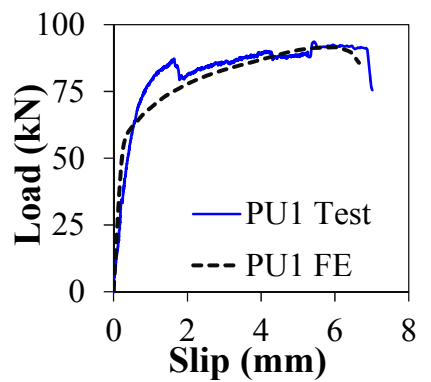

(a)

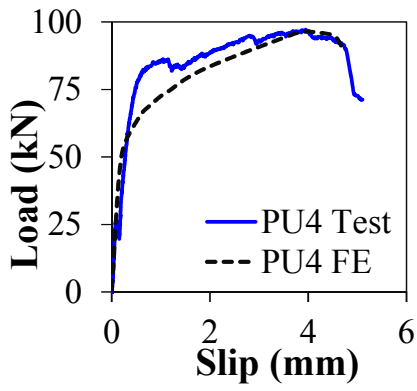

(d)

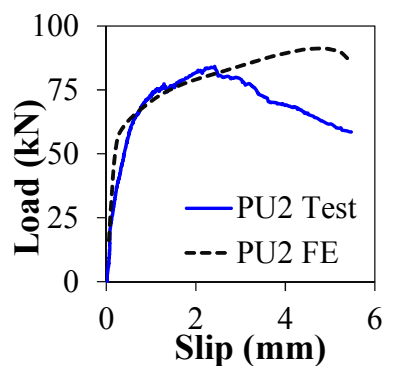

(b)

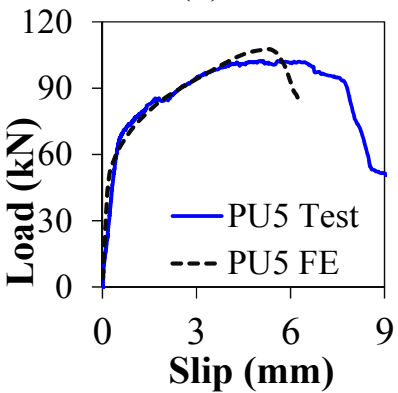

(e)

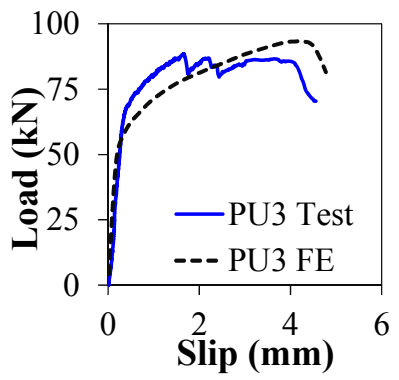

(c)

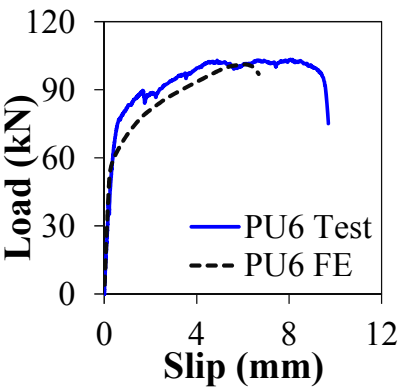

(f)

Figure 16. Comparisons of Load-slip Curves between Test and FE Simulation

Table 2. Comparisons between FE Predictions and Test Results

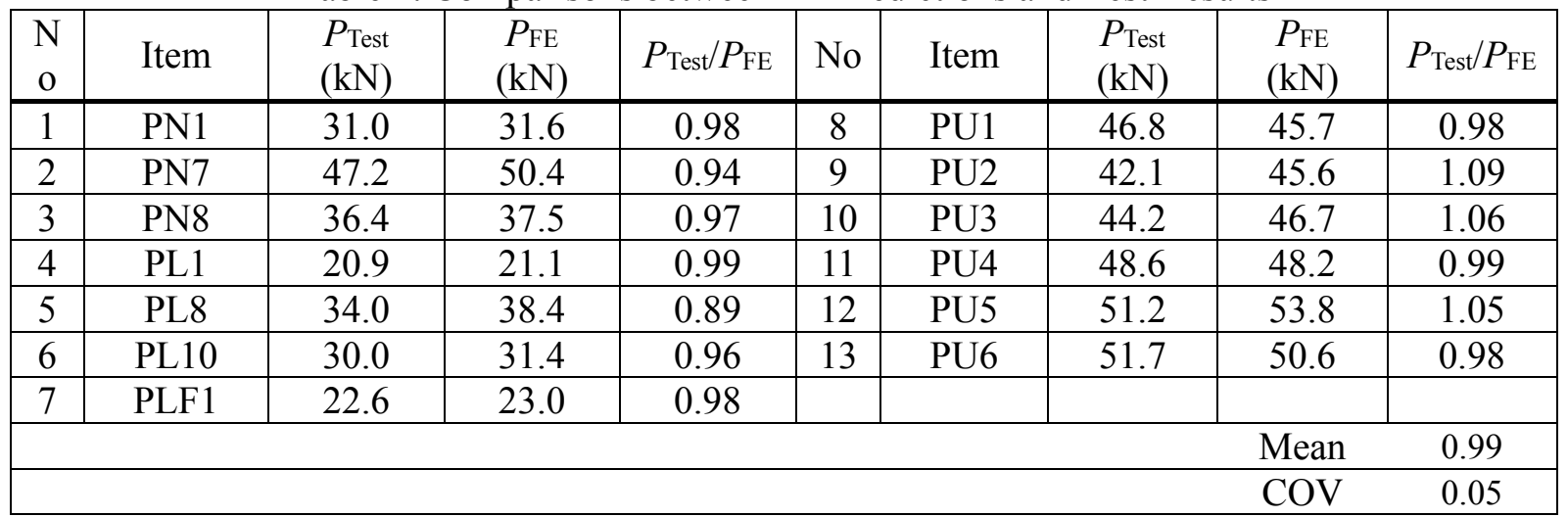

The tension-elongation behaviors of the FE model were compared with the tensile tests in Figure 17. From this figure, it can be seen that the FE model resembles well with the experimental tension-elongation curves. This implies the FE model is capable of describing the tension-elongation behavior of J-hook connectors.

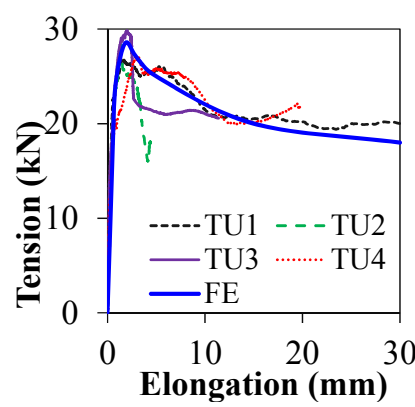

(a)

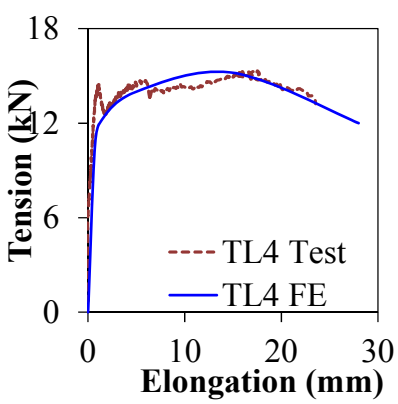

(b)

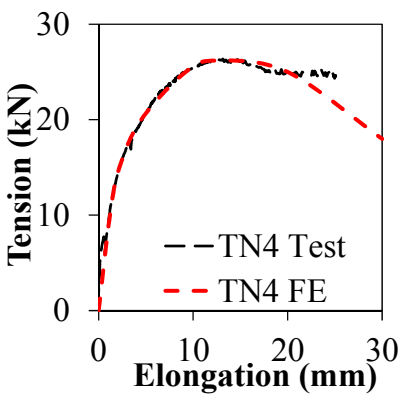

(c)

Figure 17. Comparsions of Tension-elongation Behaviors between Test and FE Simulation 
From the above verifications, it can be concluded that the developed FE model is capable of simulating the shear-slip behavior and tension-elongation behavior of the J-hook connectors. The ultimate shear and tension resistances from the FE analysis show good correlation with the test results. This developed FE model is recommended for the further analysis on shear-tension interactions of J-hook.

\subsection{Shear-tension Interaction Resistance by FE Analysis}

Table 3. Details of Specimens for Shear-tension Interaction Analysis of J-hook Connectors

\begin{tabular}{|c|c|c|c|c|c|c|c|c|}
\hline Specimen & $\begin{array}{c}\text { Push-out } \\
\text { Test }\end{array}$ & $\begin{array}{c}\text { Tensile } \\
\text { Test }\end{array}$ & $\begin{array}{c}f_{\text {ck }} \\
(\mathrm{MPa})\end{array}$ & $\begin{array}{c}E_{\mathrm{C}} \\
(\mathrm{GPa})\end{array}$ & $\begin{array}{c}\sigma_{\mathrm{y}} \\
(\mathrm{MPa})\end{array}$ & $\begin{array}{c}\sigma_{\mathrm{u}} \\
(\mathrm{MPa})\end{array}$ & $\begin{array}{c}d \\
(\mathrm{~mm})\end{array}$ & $\begin{array}{c}t \\
(\mathrm{~mm})\end{array}$ \\
\hline VTN1 & PN1 & TN1 & 48.3 & 32.5 & 353 & 405 & 9.9 & 6 \\
\hline VTN2 & PN7 & TN4 & 47.7 & 24 & 310 & 480 & 11.8 & 6 \\
\hline VTN3 & PN8 & TN5 & 33.6 & 19.5 & 310 & 450 & 11.7 & 6 \\
\hline VTL1 & PL1 & TL1 & 28.0 & 12.7 & 353 & 405 & 10.0 & 6 \\
\hline VTL2 & PLF1 & TL2 & 28.3 & 12.6 & 353 & 405 & 9.9 & 6 \\
\hline VTL3 & PL10 & TL5 & 19.9 & 15.0 & 310 & 450 & 11.7 & 6 \\
\hline VTL4 & PL8 & TL6 & 49.6 & 19.0 & 310 & 450 & 10.0 & 6 \\
\hline VTU1 & PU1 & TU3 & 62.6 & 16.5 & 310 & 465 & 11.8 & 4 \\
\hline VTU2 & PU2 & TU1 & 62.6 & 16.5 & 310 & 465 & 11.8 & 6 \\
\hline VTU3 & PU3 & TU3 & 62.6 & 16.5 & 310 & 465 & 11.8 & 8 \\
\hline VTU4 & PU4 & TU5 & 62.6 & 16.5 & 310 & 465 & 11.8 & 12 \\
\hline VTU5 & PU5 & TU2 & 62.6 & 16.5 & 310 & 465 & 11.8 & 6 \\
\hline VTU6 & PU6 & TU2 & 62.6 & 16.5 & 310 & 465 & 11.8 & 6 \\
\hline
\end{tabular}

*VTN1-V denotes shear, T denotes tension, $\mathrm{N}$ denotes normal weight concrete, 1 denotes number; $f_{\mathrm{ck}}=$ compressive strength of concrete; $E_{\mathrm{c}}=$ elastic modulus; $\sigma_{\mathrm{y}}=$ yield strength of connector; $\sigma_{\mathrm{u}}=$ ultimate strength of connector; $d=$ diameter of connector; $t=$ thickness of steel plate in the specimen.

Experimental study on resistance under combination of shear and tension is limited by the test apparatus and proved to be very costly. The proposed FE model provides an alternative method to investigate the shear-tension interaction of J-hook connectors as shown in Figure 18. Two loading steps, tension step and followed shear step, were successively applied to the specimens to obtain different shear-tension resistance couples by the FE analysis.

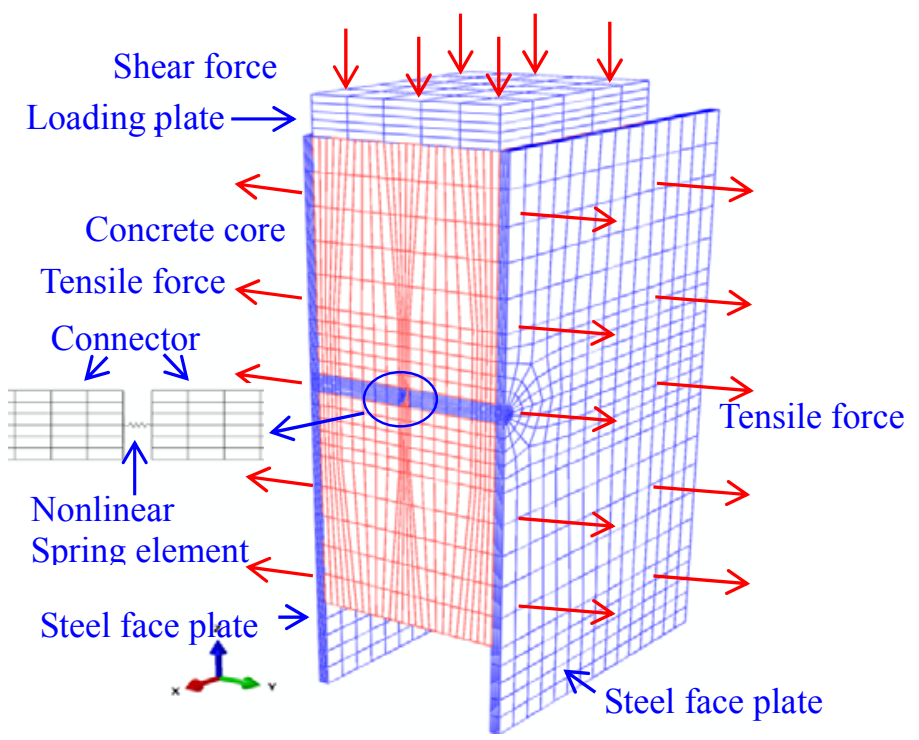

Figure 18. FE Model for Shear-tension Interaction Analysis of J-hook 
In this paper, FE analyses on shear-tension interaction of thirteen specimens were carried out. Details of these thirteen specimens are tabulated in Table 3.

For each analysis case, the push-out tests and tension resistances obtained from the tests reported in Section 3.2 and 3.3 were given in this table. The shear-tension interaction resistances of J-hook connectors obtained from the FE analysis are tabulated in Table 4. From this table, it can be seen that the tension and shear resistance interact each other. As the tension resistance increases from zero to the ultimate tension capacity, the shear resistance of the J-hook decreases from the ultimate resistance to zero in a parabolic relationship. The shear especially decreases dramatically when the tension resistance nearly achieves the ultimate tension capacity.

\section{COMPARISON OF RESULTS FROM FE ANALYSIS AND DESIGN EQUATIONS}

The generalized shear-tension diagrams obtained from the FE analysis and tests were compared with the predictions by the design formulae in Figures. 19-21.

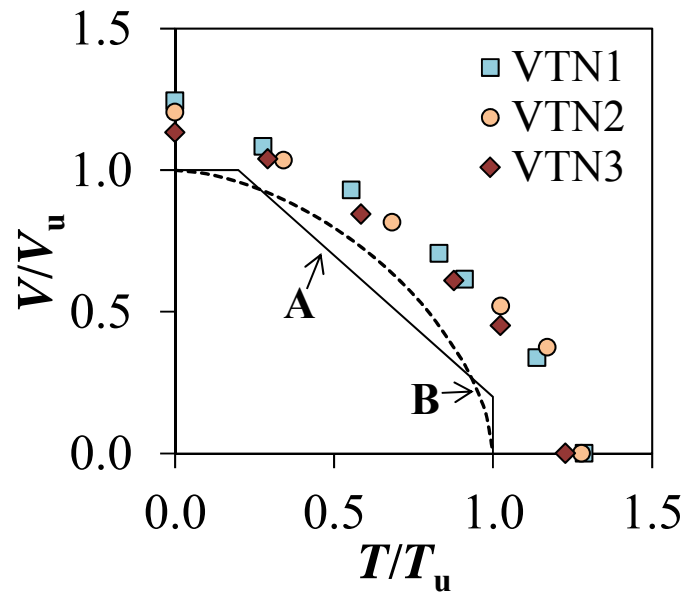

Figure 19. Shear-tension Interaction Resistance of J-hook Connectors in NWC (Prediction curves A and B were predicted by Eqs. 9 and 10, respectively)

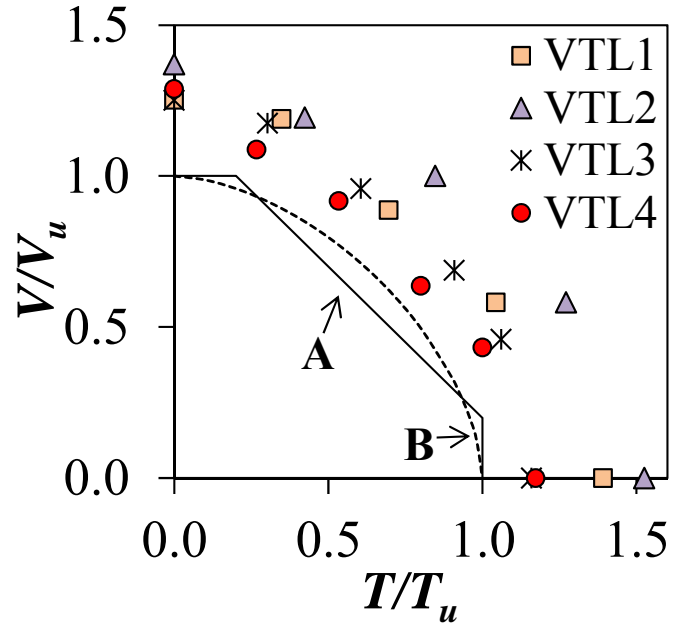

Figure 20. Shear-tension Interaction Resistance of J-hook Connectors in LWC

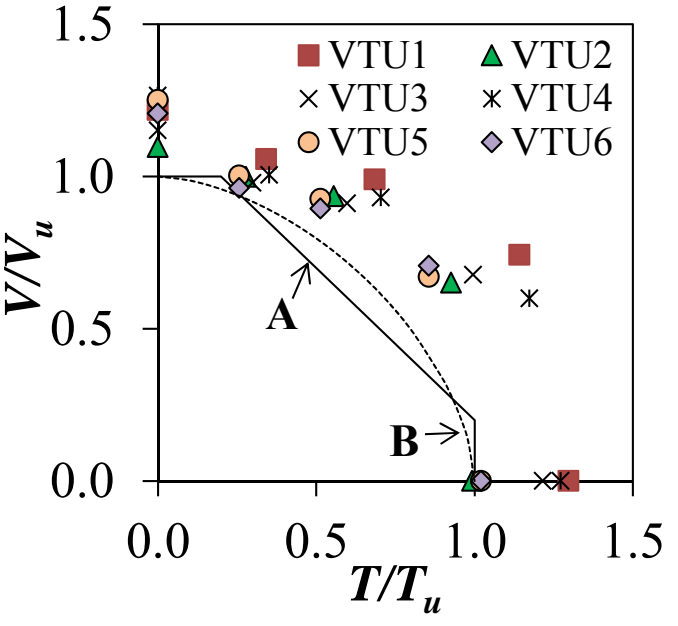

Figure 21. Shear-tension Interaction Resistance of J-hook Connectors in ULCC 
From these figures and Table 4, it can be found that (1) both Eq. 9 and 10 were capable of evaluating the shear-tension interaction resistance of the J-hook connectors in NWC, LWC, and ULCC; (2) Eqs. 9 and 10 offer more conservative predictions to NWC compared with predictions with specimens with LWC and ULCC; (3) the conservative predictions for specimens with LWC and ULCC were caused by the addition of fibers in the LWC and ULCC that was not considered in the design equations; (4) compared with specimens with LWC and ULCC, the variance of the predictions for specimens with NWC was smaller. This larger variance of the predictions for specimens with LWC and ULCC was also caused by the addition of the fiber and variance of their strengths.

Table 4. Shear-tension Resistances of J-hook Connectors by FE Analysis and Tests

\begin{tabular}{|c|c|c|c|c|c|c|c|c|c|}
\hline Specimen & $\begin{array}{c}T \\
(\mathrm{kN})\end{array}$ & $\begin{array}{c}V \\
(\mathrm{kN})\end{array}$ & $T / T_{\mathrm{u}}$ & $V / V_{\mathrm{u}}$ & Specimen & $\begin{array}{c}T \\
(\mathrm{kN})\end{array}$ & $\begin{array}{c}V \\
(\mathrm{kN})\end{array}$ & $T / T_{\mathrm{u}}$ & $V / V_{\mathrm{u}}$ \\
\hline \multirow[t]{2}{*}{$\overline{\text { VTN1 }}$} & 0.0 & $31.0^{\mathrm{t}}$ & 0.00 & 1.24 & \multirow[t]{2}{*}{$\overline{\text { VTL1 }}$} & 0.0 & $20.9^{t}$ & 0.00 & 1.25 \\
\hline & 4.7 & 27.0 & 0.28 & 1.08 & & 4.0 & 19.9 & 0.35 & 1.19 \\
\hline \multirow{5}{*}{$\begin{array}{l}T_{\mathrm{u}}=24.9 \\
T_{\mathrm{u}}=17.1\end{array}$} & 9.5 & 23.1 & 0.55 & 0.93 & $V_{\mathrm{u}}=16.7$ & 8.0 & 14.8 & 0.70 & 0.89 \\
\hline & 14.2 & 17.6 & 0.83 & 0.71 & \multirow[t]{2}{*}{$T_{\mathrm{u}}=11.5$} & 12.0 & 9.7 & 1.04 & 0.58 \\
\hline & 15.6 & 15.3 & 0.91 & 0.61 & & $16.0^{\mathrm{t}}$ & 0.0 & 1.39 & 0.00 \\
\hline & 19.5 & 8.4 & 1.14 & 0.34 & \multirow[t]{2}{*}{ VTL2 } & 0.0 & $22.6^{\mathrm{t}}$ & 0.00 & 1.37 \\
\hline & $22.0^{\mathrm{t}}$ & 0.0 & 1.29 & 0.00 & & 5.0 & 19.7 & 0.42 & 1.19 \\
\hline \multirow{3}{*}{$\begin{array}{c}\text { Unit: } \\
\text { kN }\end{array}$} & & & & & $V_{\mathrm{u}}=16.5$ & 10.0 & 16.5 & 0.85 & 1.00 \\
\hline & & & & & $T_{\mathrm{u}}=11.8$ & 15.0 & 9.6 & 1.27 & 0.58 \\
\hline & & & & & & $18.0^{\mathrm{t}}$ & 0.0 & 1.53 & 0.00 \\
\hline \multirow[t]{2}{*}{ VTN2 } & 0.0 & $47.2^{t}$ & 0.00 & 1.20 & \multirow[t]{6}{*}{ VTL3 } & 0.0 & $30.0^{t}$ & 0.00 & 1.25 \\
\hline & 7.0 & 40.6 & 0.34 & 1.04 & & 4.0 & 28.2 & 0.30 & 1.18 \\
\hline$V_{\mathrm{u}}=39.2$ & 14.0 & 32.0 & 0.68 & 0.82 & & 8.0 & 23.0 & 0.61 & 0.96 \\
\hline \multirow[t]{3}{*}{$T_{\mathrm{u}}=20.5$} & 21.0 & 20.4 & 1.02 & 0.52 & & 12.0 & 16.5 & 0.91 & 0.69 \\
\hline & 24.0 & 14.7 & 1.17 & 0.38 & & 14.0 & 11.0 & 1.06 & 0.46 \\
\hline & $26.2^{\mathrm{t}}$ & 0.0 & 1.28 & 0.00 & & $15.3^{\mathrm{t}}$ & 0.0 & 1.16 & 0.00 \\
\hline \multirow[t]{2}{*}{ VTN3 } & 0.0 & $36.4^{\mathrm{t}}$ & 0.00 & 1.13 & \multirow[t]{6}{*}{ VTL4 } & 0.0 & $34.0^{t}$ & 0.00 & 1.29 \\
\hline & 5.0 & 33.4 & 0.29 & 1.04 & & 4.0 & 28.7 & 0.27 & 1.09 \\
\hline$V_{\mathrm{u}}=32.1$ & 10.0 & 27.1 & 0.58 & 0.84 & & 8.0 & 24.2 & 0.53 & 0.92 \\
\hline \multirow[t]{3}{*}{$T_{\mathrm{u}}=17.1$} & 15.0 & 19.6 & 0.88 & 0.61 & & 12.0 & 16.8 & 0.80 & 0.64 \\
\hline & 17.5 & 14.5 & 1.02 & 0.45 & & 15.0 & 11.4 & 1.00 & 0.43 \\
\hline & $21.0^{\mathrm{t}}$ & 0.0 & 1.23 & 0.00 & & $17.6^{\mathrm{t}}$ & 0.0 & 1.17 & 0.00 \\
\hline \multirow[t]{2}{*}{ VTU1 } & 0.0 & $46.8^{t}$ & 0.00 & 1.42 & \multirow[t]{2}{*}{ VTU4 } & 0.0 & $48.6^{t}$ & 0.00 & 1.48 \\
\hline & 7.5 & 40.6 & 0.34 & 1.23 & & 7.5 & 38.6 & 0.34 & 1.17 \\
\hline$V_{\mathrm{u}}=32.9$ & 15.0 & 38.0 & 0.68 & 1.16 & $V_{\mathrm{u}}=32.9$ & 15.0 & 35.8 & 0.68 & 1.09 \\
\hline \multirow[t]{2}{*}{$T_{\mathrm{u}}=21.9$} & 25.0 & 26.4 & 1.14 & 0.80 & \multirow[t]{2}{*}{$T_{\mathrm{u}}=21.9$} & 25.0 & 23.0 & 1.14 & 0.70 \\
\hline & $28.4^{\mathrm{t}}$ & 0.0 & 1.30 & 0.00 & & $27.1^{\mathrm{t}}$ & 0.0 & 1.24 & 0.00 \\
\hline \multirow[t]{2}{*}{ VTU2 } & 0.0 & $42.1^{\mathrm{t}}$ & 0.00 & 1.28 & \multirow[t]{2}{*}{ VTU5 } & 0.0 & $51.2^{\mathrm{t}}$ & 0.00 & 1.46 \\
\hline & 7.5 & 38.3 & 0.34 & 1.17 & & 7.5 & 41.0 & 0.25 & 1.17 \\
\hline$V_{\mathrm{u}}=32.9$ & 15.0 & 35.9 & 0.68 & 1.09 & $V_{\mathrm{u}}=35.0$ & 15.0 & 37.9 & 0.51 & 1.08 \\
\hline \multirow[t]{2}{*}{$T_{\mathrm{u}}=21.9$} & 25.0 & 25.0 & 1.14 & 0.76 & \multirow[t]{2}{*}{$T_{\mathrm{u}}=29.5$} & 25.0 & 27.4 & 0.85 & 0.78 \\
\hline & $26.8^{t}$ & 0.0 & 1.22 & 0.00 & & $29.8^{\mathrm{t}}$ & 0.0 & 1.01 & 0.00 \\
\hline \multirow[t]{2}{*}{ VTU3 } & 0.0 & $44.2^{t}$ & 0.00 & 1.34 & \multirow[t]{2}{*}{ VTU6 } & 0.0 & $51.6^{\mathrm{t}}$ & 0.00 & 1.41 \\
\hline & 7.5 & 37.6 & 0.34 & 1.14 & & 7.5 & 41.2 & 0.25 & 1.13 \\
\hline$V_{\mathrm{u}}=32.9$ & 15.0 & 35.0 & 0.68 & 1.06 & $V_{\mathrm{u}}=36.6$ & 15.0 & 38.3 & 0.51 & 1.05 \\
\hline \multirow{2}{*}{$T_{\mathrm{u}}=21.9$} & 25.0 & 26.0 & 1.14 & 0.79 & \multirow[t]{2}{*}{$T_{\mathrm{u}}=29.5$} & 25.0 & 30.2 & 0.85 & 0.83 \\
\hline & $30.5^{\mathrm{t}}$ & 0.0 & 1.39 & 0.00 & & $29.8^{\mathrm{t}}$ & 0.0 & 1.01 & 0.00 \\
\hline
\end{tabular}

tData from tests; $V_{\mathrm{u}}=$ predicted ultimate shear resistance; $T_{\mathrm{u}}=$ predicted ultimate tension resistance.

From the above observation, it can be concluded that the proposed design formulae are capable of describing the shear-tension interaction behaviors of J-hook connectors in SCS sandwich structure with NWC, LWC, and ULCC. 


\section{CONCLUSIONS}

This paper investigates the ultimate resistance behaviors of new type of J-hook connectors subjected to pure shear, pure axial tension, and combined shear and tensile forces occurred at the steel and concrete interfaces of sandwich structure.

Thirty push-out tests were carried out to determine the longitudinal shear resistance of J-hook connectors embedded in different grades of concretes. The push-out test results were used to validate the design equations in order to predict the maximum shear resistance of J-hook connectors. Equation 2 offers reasonably accurate and conservative prediction of the shear resistance of the J-hook connector compared to the results obtained from the Eurocode method, which was developed mainly for headed stud connectors.

Eighteen tensile tests were carried out to investigate the tension resistance of J-hook connectors embedded in various types of concrete. The proposed design equations were found to be capable of predicting the tension resistance of J-hook connectors with acceptable accuracy (test-to-prediction ratio: mean value $=1.34 ; \mathrm{COV}=0.14)$. The equations neglect the beneficial effects of fibers in the core material and therefore the prediction is on the conservative side.

Three-dimensional nonlinear finite element model was developed to obtain the shear-tension interaction resistance of J-hook connectors. The FE model was validated by push-out tests and tensile tests. The FE model may be used to simulate the shear-slip behavior and tension-elongation behavior of the J-hook connectors with reasonably good accuracy compared to the test results. Shear-tension interaction resistance couples of J-hook connectors were obtained from FE analyses. Design equations on shear-tension interaction of J-hook connectors were proposed based on calibration with FE analysis and test results. Finally, Equations 9 and 10 were recommended to evaluate the combined shear-tension resistance of the J-hook connectors for steel concrete steel sandwich structures.

\section{ACKNOWLEDGMENTS}

The research described herein was funded by the Maritime and Port Authority of Singapore, and supported by the American Bureau of Shipping (ABS) and National University of Singapore under research project titled "Curved steel-concrete-steel sandwich composite for Arctic region" (Project No. R-302-501-002-490).

\section{REFERENCES}

[1] Solomon, S.K., Smith, D.W. and Cusens, A.R., "Flexural Tests of Steel-concrete-steel Sandwiches", Magazine of Concrete Research, 1976, Vol. 28, No. 94, pp. 13-20.

[2] Malek, N., Machida, A., Mutsuyoshi, H. and Makabe, T., "Steel-concrete Sandwich Members without Shear Reinforcement", Transactions of Japan Concrete Institute, 1993, Vol. 15, No.2, pp. 1279-1284.

[3] Narayanan, R., Wright, H.D., Francis, R.W. and Enans, H.R., "Double Skin Composite Construction for Submerged Tube Tunnels", Steel Construction Today, 1987, Vol. 1, pp. 185-189.

[4] Xie, M. and Chapman, J.C., "Development in Sandwich Construction", Journal of Constructional Steel Research, 2006, Vol. 62, No. 11, pp. 1123-1133. 
[5] Xie, M., Foundoukos, N. and Chapman, J.C., "Static Tests on Steel-Concrete-Steel Sandwich Beams", Journal of Constructional Steel Research, 2007, Vol. 63, No. 6, pp. 735-750.

[6] Liew, J.Y.R., Sohel, K.M.A. and Koh, C.G., "Impact Tests on Steel-Concrete-Steel Sandwich Beams with Lightweight Concrete Core", Engineering Structures, 2009, Vol. 31, No. 9, pp.2045-2059.

[7] Liew, J.Y.R. and Wang, T.Y., "Novel Steel-Concrete-Steel Sandwich Composite Plates Subject to Impact and Blast Load", Advances in Structural Engineering, 2011, Vol. 14, No. 4, pp. 673-687.

[8] Dai, X.X. and Liew, J.Y.R., "Fatigue Performance of Lightweight Steel-Concrete-Steel Sandwich Systems", Journal of Constructional Steel Research, 2010, Vol. 66, No. 2, pp. 256-276.

[9] Viest, I.M., "Investigation of Stud Shear Connectors for Composite Concrete and Steel T-beams", Journal of the American Concrete Institute, 1956, Vol. 27, No. 8, pp.875-91.

[10] Driscoll, G.G. and Slutter, R.G. "Research on Composite Design at Lehigh University", In: Proceedings of the National Engineering Conference, Chicago (IL): American Institute of Steel Construction, 1961, pp. 18-24.

[11] Chinn, J., "Pushout Tests on Lightweight Composite Slabs", Engineering Journal, AISC, 1965, Vol. 2, No. 4, pp.129-34.

[12] Steele, D.H., "The Use of Nelson Studs with Lightweight Aggregate Concrete in Composite Construction", M.S. Thesis, Boulder (CO): University of Colorado; 1967.

[13] Davies, C., "Small-scale Push-out Tests on Welded Stud Shear Connectors", Concrete, 1967, Vol. 1, No. 9, pp. 311-6.

[14] Mainstone, R.J. and Menzies, J.B., "Shear Connectors in Steel Concrete Composite Beams for Bridges", Concrete, 1967, Vol. 1, No. 9, pp. 291-302.

[15] Goble, G.G., "Shear Strength of Thin Flange Composite Specimen", Engineering Journal, AISC, 1968, Vol. 5, No. 2, pp. 62-5. 2nd Quarter.

[16] Topkaya, C., Yura, J.A. and Williamson, E.B., "Composite Shear Stud Strength at Early Concrete Ages", Journal of Structural Division, ASCE, 2004, Vol. 130, No. 6, pp. 952-60.

[17] Ollgaard, J.G., Slutter, R.G. and Fisher, J.W., "Shear Strength of Stud Connectors in Lightweight and Normal-weight Concrete”, Engineering Journal, AISC, 1971, Vol. 8, No.2, pp. 55-64.

[18] Oehlers, D.J. and Bradford, M.A., "Composite Steel and Concrete Structural Members: Fundamental Behavior", Oxford U.K: Pergamon; 1995.

[19] An, L. and Cederwall, K., "Push-out Tests on Studs in High Strength and Normal Strength Concrete", Journal of Constructional Steel Research, 1996, Vol. 36, No. 1, pp. 15-29.

[20] Pallarés, L. and Hajjar, J.F., "Headed Steel Stud Anchors in Composite Structures, Part I: Shear", Journal of Constructional Steel Research, 2010, Vol. 66, No.2, pp.198-212.

[21] Cook, R.A., Collins, D.M., Klingner, R.E. and Polyzois, D., "Load-deflection Behavior of Cast-in-place and Retrofit Concrete Anchors", ACI Structural Journal, 1992, Vol. 89, No. 6, pp. 639-49.

[22] Cook, R.A., Kunz, J., Fuchs, W. and Konz, C.D., "Behavior and Design of Single Adhesive Anchors under Tensile Load in Uncracked Concrete", ACI Structural Journal, 1996, Vol. 95, No. 1, pp. 9-26.

[23] Zamora, N.A., Cook, R.A., Konz, R.C. and Consolazio, G.R., "Behavior and Design of Single, Headed and Unheaded, Grouted Anchors under Tensile Load", ACI Structural Journal, 2003, Vol. 100, No. 2, pp. 222-30.

[24] Shirvani, M., Klingner, R.E. and Graves III, H.L., "Breakout Capacity of Anchors in Concrete, Part 1: Tension”, ACI Structural Journal, 2004, Vol. 101, No.6, pp.812-20.

[25] Eligehausen, R. and Balogh, T., "Behavior of Fasteners Loaded in Tension in Cracked Reinforced Concrete”, ACI Structural Journal, 1995, Vol. 92, No. 3, pp. 365-79. 
[26] Eligehausen, R., Cook, R.A. and Appl, J., "Behavior and Design of Adhesive Bonded Anchors", ACI Structural Journal, 2006, Vo. 103, No. 6, pp. 822-31.

[27] Fuchs, W., Eligehausen, R. and Breen, J.E., "Concrete Capacity Design Approach for Fastening to Concrete", ACI Structural Journal, 1995, Vol. 92, No. 1, pp.73-94.

[28] Bode, H. and Roik, K., "Headed Studs- Embedded in Concrete and Loaded in Tension", American Concrete Institute SP 103-4. Farmington Hills (MI): American Concrete Institute; 1987, pp. 61-88.

[29] Balogh T., Kovácsházy G. and Frigy A., "Pull-out Tests on Steel Embedment in Concrete", In: Anchors in concrete -Design and behavior, ACI SP130-9. Farmington Hills (MI): American Concrete Institute; 1991, pp. 221-33.

[30] Klingner R.E. and Mendonca J.A., "Tensile Capacity of Short Anchor Bolts and Welded Studs: A Literature Review", ACI Structural Journal, 1982, Vol. 79, No.4, pp.270-9.

[31] Pallares, L. and Hajjar, J.F., "Headed Steel Stud Anchors in Composite Structures, Part II: Tension and Interaction", Journal of Constructional Steel Research, 2010, Vol. 66, No. 2, pp. 213-228.

[32] McMakin, P.J., Slutter, R.G. and Fisher, J.W., "Headed Steel Anchor under Combined Loading”, Engineering Journal, AISC 1973; (Second Quarter):43-52.

[33] Saari, W.K., Hajjar, J.F., Schultz, A.E. and Shield, C.K., "Behaviour of Shear Studs in Steel Frames with Reinforced Concrete Infill Walls", Journal of Constructional Steel Research, 2004, Vol. 60, No. 10, pp. 1453-1480.

[34] Mirza, O. and Uy, B., "Effects of the Combination of Axial and Shear Loading on the Behavior of Headed Stud Steel Anchors”, Engineering Structures, 2006, Vol. 32, No. 1, pp. 93-105.

[35] Yan, J.B., Liew, J.Y.R., Sohel, M.A. and Zhang, M.H., "Push-out Tests on J-hook Connectors in Steel-Concrete-Steel Sandwich Structure", Materials and Structures, 2014, Vol. 47, No. 10, pp. 1693-1714.

[36] PCI, "PCI design handbook, 6th edition", Prestressed Concrete Institute, 2004, Chicago.

[37] American Concrete Institute (ACI) Committee 318, "Building Code Requirements for Structural Concrete (ACI318-02) and Commentary (ACI 318R-02)", American Concrete Institute, 2002, Detroit, MI.

[38] Liew, J.Y.R. and Sohel, K.M.A., "Lightweight Steel-Concrete-Steel Sandwich System with J-hook Connectors", Engineering Structures, 2009, Vol. 31, No. 5, pp. 1166-1178.

[39] Wang, J.Y., Zhang, M.H., Li, W., Chia, K.S. and Liew, J.Y.R., "Stability of Cenospheres in Lightweight Cement Composites in Terms of Alkali-silica Reaction", Cement and Concrete Research, 2012, Vol. 42, No. 5, pp. 721-727.

[40] British Standards Institution BS EN 1994: Design of Composite Steel and Concrete Structures-Part 1-1 General Rules and Rules for Buildings, 2004, London, UK.

[41] CEB-FIP. CEB-FIP Model Code for Concrete Structures, 3rd Edition, Comité Euro-International du Béton/FédérationInternationale de la Précontrainte, 1978, Paris.

[42] ACI Committee 349, Code Requirements for Nuclear Safety Related Concrete Structures (ACI 349-01) and Commentary (ACI 349R-01). ACI, 2001, Farmington Hills.

[43] British Standards Institution BS EN 1992:. Design of Concrete Structures, Part 1-2:General Rules and Rules for Buildings, 2004, BSI, London.

[44] British Standards Institution BS EN 1993: Design of Steel Structures. Part 1-1: General Rules and Rules for Buildings. 2005, BSI, London.

[45] Xie, M., Foundoukos, N. and Chapman, J.C., "Experimental and Numerical Investigation on the Shear Behaviour of Friction-welded Bar-plate Connections Embedded in Concrete", Journal of Constructional Steel Research, 2005, Vol. 61, No. 5, pp. 625-649.

[46] Yan, J.B., Liew, J.Y.R., Zhang, M.H., "Tensile resistance of J-hook connectors in Steel-Concrete-Steel sandwich composite structure. Journal of Constructional Steel Research, 2014, Vol. 100, pp. 146-162. 